\title{
Organizational and Managerial Mechanisms for Resolving Social Conflicts: Legal Aspect
}

Leonid A. Garanin

\author{
Polina S. Starygina
}

Svetlana A. Utrosina

Olga V. Glushkova

Mari State University, Yoshkar-Ola, Russia

Email: poly222@yandex.ru

Doi:10.5901/mjss.2015.v6n3s7p53

\section{Abstract}

In this article the author solves the problems of managements of social conflicts with the help of regulatory mechanisms. Manage existing conflict involves settlement, resolution or even suppression of the latter in the interests of society as a whole or its individual subjects. Good governance adds conflict to the process form, capable of minimizing losses of various kinds. One of most important public institutions, the effect of which can be directed on elimination of contradictions of the conflict parties, conflict management and resolution are legal provisions. The article presents the conceptualization and justification the critical role of law as a universal mechanism of regulation of social conflicts, an analysis of alternative methods of conflict resolution. Identified and practically justified the possibilities and prospects of application of legal norms under negotiation, mediation or arbitration. The question of the impact of legal norms on social conflict, its structure and dynamics is discussed. Researching the problem of solving conflict, author analyze some specific situations and identifies opportunities of overcoming social conflicts.

Keywords: social conflict, rules of law, legal means of resolving social conflicts, alternative means of resolving conflicts

\section{Introduction}

The history of human civilization is full of different sorts of conflicts. Some conflicts covered whole continents and a lot of countries and nations, some involved big and small social communities, and the other once are happened between single people. For centuries people were dreaming about the ideal and harmonious community. Since ancient times they were trying to solve contradictions and create a conflict-free society.

In the end of $19^{\text {ththe }}$ problem of management of social conflict became very topical for many human sciences. In the west, the enhanced process of the formation of science conflict is noticed. The Science conflict studies different social reasons, structure, dynamics and the functions of the conflict, also the development of solving mechanisms. The $20^{\text {th }}$ century placed the science conflict at the top of all the humanitarian and social sciences.

The significant contribution in social conflict was made by well-known Russian scientists: A.V. Dmitriev, A.G. Zdravomyslov, G.I. Kozarev, V.N. Kudryavtsev, U.G. Zaprudskii, V.I. Speranskii and others.

The problems of management of social conflict are mentioned in different articles of A.N.Chumikova, M.M.Lebedevoi, D.S. Klementievoi and others.

The great contribution to the development of conflict resolution and to the studying of the problems of interaction of law and social conflict was made by staff of the Conflicts resolution Center at the head of E.I. Stepanov.

Some other scientists such as: V.S. Jerebin, O.V. Boikov, N.N. Varlamova, they all are working at these problems of managing the social conflict.

A lot of theoretical and practical material for the application of the main ways of managing and resolving the social conflict is received from specialized books and journals.

It is worth mentioning some foreign authors: R. Dahrendorf, L. Kozer, W. Kennedy, R. Fisher, E. Burn .The managing of the conflict involves the arrangement and resolution of individual subjects. The efficient management gives a conflicting process forms that can ensure minimizing losses. The main task is to reach a consensus and a compromise.

The Law is one of the most important public institutions whose effect can be directed to the management and 
resolution of conflict. In this connection, the analysis and interpretation of mechanisms of the resolution some social conflicts is quite topical. Besides, it is very important to analyze the influence of the rules of law on the settlement process or on a resolution of any kind of social conflict, also to research the methods of managing and resolving any conflict situations, such as negotiations, arbitration and arbitration courts. It is also important to show the prospects for the development of legal institutions as a constructive basis for resolution social conflicts.

The practical values form practical recommendations for further study the opportunities of using the law in organizational and managerial mechanisms of social conflicts.

Our courts of justice appear to be the most common way of resolving the conflict, occasionally they are overwhelmed with many different cases, including such, where the circumstances of the defendant are not satisfied for some reason (for example, the typical reason of non-execution is a lack of money) Even though the court justice admits the defendant's guilt, would oblige him to fulfill his obligation, would impose penalties, that will not guarantee the execution of judge's decision. As a result people's nihilism appears, the economic instability in society redoubles.

Nowadays everything is directed to solve such problems, that is why during this period the role of alternative procedures should increase.

All over the world there is a practice of alternative means of dispute resolution with help of intermediary, negotiations and arbitration. In many cases these methods are the actual output of the situation since they do not require significant financial and technical spending.

However, there are some peculiarities of using these methods. For the successful development of the arbitration and other forms and methods of alternative proceedings there is not enough legislative framework, financial resources and a positive attitude in our society in total.

The norms of the Constitution of the Russian Federation, which secure the freedom of economical and business activity, the freedom of contract to a certain extent assume also the freedom in settlement 0 controversy between the subjects. We can say that alternative means of resolving conflicts could be applicable to all civilian cases and certain criminal cases.

Thus, the purpose of the research is to find out the possibilities and perspective of using the law in organizational and managerial mechanisms of social conflicts.

Achieving this goal involves the following tasks:

- the specification of the social nature of law as a regulator of social relations, its main features and functions;

- the identification of a legal mechanism for managing the public relations;

- the specification of areas and limits of the legal regulation in the relationships of people;

- $\quad$ the identification of nature and essence of the conflict as a phenomenon of social life;

- tracking mechanisms of managerial influence of law on all sides of the conflict;

- the resolution of the main legal ways of managing, which exist in the Russian legislation;

- $\quad$ the features of the alternative ways of solving the conflict, the practice of which exist in Russia and abroad;

- the allocation of main problems of application of the legal means of solving the conflicts, which exist in our country;

- the consideration of possible solutions and perspectives of these problems and also their further development;

The main hypothesis of researching included the following issues:

1) The law is one of the most important instruments of managing the social conflict.

2) The definition "Managing the social conflict" should include the detection, prognostication, prevention, notification, attenuation, managing and resolution of the conflict.

3) The application of the law, resolution and managing the conflict leads to the fact that all procedures are carried out according to the law.

4) There are some problems which come into being because of the resolving social conflicts with the help of law:

a) the problem of efficiency of the administrative activity of the head

b) the lack of knowledge about such ways of resolving the conflict

c) the absence of special knowledge about the opportunities and the order of using such means

d) the problem of Psychology in a conflict- negative emotions, alertness to each other

e) a stereotype about the court justice, that it is the only agency which can make fair decisions about the dispute

5) The ways of solving the problems are:

a) improving the management training, the specialists, who work with participants of a social conflict ( for example lawyer);

b) an improvement of the regulatory framework for the use of means of conflict resolution; 
c) to get the society familiar with the fact how to solve a social conflict with minimal losses and how to apply the rules of law correctly;

d) a scientific systematization of knowledge about the opportunities and practice of using the means of conflict resolution, an exchange of relevant experience with foreign partners;

6) As the prospects for the development of means of resolving the conflict:

a) the creation and the development of organizations which provide mediation services to both individuals and legal entities in solving any kind of social conflict;

b) an increase of the role of arbitration courts in resolving commercial disputes;

c) an increase of the role of labor arbitration, commissions on labor disputes;

d) reorientation of legal advice, firms, private lawyers at the pre-trial resolution of conflicts that arise;

e) reducing the role of the court and other administrative authorities in managing the social conflict;

\section{Methods}

The metrological basis of study consists of two major reference points:

1) the analysis of common problems and achievements of contemporary conflict and their specification;

2) meaningful analysis of the problems, which related to the disclosure of the task and afterwards the technological conclusions from this analysis;

As research methods there were used: the functional approach to the understanding of law and subjective approach to the understanding of social conflict;

According to this, literary sources, the legal acts of Russian Federation, the great theoretical and practical material was examined and analyzed;

\section{Results and Discussion}

The analysis of the various interpretations of law, that was given by Russian and foreign scientists shows us that the understanding of the problem of law is very important. Despite the diversity of this social phenomenon we can distinguish the most important and necessary evidence of law.

The functions of the law are considered in the system of social management and the connection with economical, social, political and ideological factors of social development. The main and defining function is the function of integration of social formations (groups, classes, nations and the whole society). The main function of the law is the social regulation of human activity, ensuring the protection of their interests.

The right can have a real impact on the activity and human's behavior as well as it can put in force progressive social change. This mechanism represents the process of legal regulation. The legal regulation is a special legal effect on the subject's behavior, this is the summation of legal means and with their help the regulation of social relations is carried out. These means include: the rules of law, subjective rights and responsibilities, legal facts, organizational activities of the state. The specified properties of the law as a regulator of social relations allow them to have some managerial impact.

The conflict is a clash between two or more parties, who are aware of their goals mismatch. Among all the possible types of conflict it is worth noting the social conflict. The social conflict is a type of social interaction the cause of which is the contradiction between the needs, interests, goals, social status, roles and functions of social subjects. In the conflict we have a clash of real subjects and not a clash of interests or goals. Therefore, the subject-activity approach is topical nowadays. This approach is based on consideration of the concept of activity in the specificity of social being. The activity is an expression of the activism of a social subject to its surroundings. The connection between the subject and its surroundings can be different. This fact gives a person or a community of people the opportunity of self-determination and requires to establish such a connection with the surroundings. When two subjects confront each other, the contradictory relationship between them takes the form of conflict. From this point of view social conflict is a confrontation between subjects. If we take into account all the points of view on the nature of social conflict, we can distinguish the main points which characterize the conflict. At first, the conflict is a struggle between individuals or group of people. Secondly, the reason for this dispute is a mismatch of interests of different groups as well as differences in the methods of achieving this goal. The conflict is a special type of social interaction, the subjects of which are the individuals, groups and organizations. The conflict is a kind of part of the social life, one of the forms of social relations between the subjects. The main value of the right is that it is capable in a certain way to control the behavior of people in society, have a real impact on their activities and on the social conflict. Among the existing types of social conflict, it is necessary to 
distinguish a legal conflict. This is a conflict in which the dispute in any way is related to the legal relationship of the parties. Legal nature may have almost all the elements of the conflict. This is the motivation of the conflict, participants of the conflict, the conflict situation, the object and subject of the conflict. The institutionalization is the first action in the management of social conflict. It suggests the presence or development of specific rules, on which is based the process of finding solution and conflict resolution. These rules include a variety of procedures, sanctions and norms which are legitimate under certain conditions. The regulation of the conflict will be completely institutionalized if all the basic rules of behavior in it are legally formalized, controlled by sanctions and its members. The next stage of conflict management can be called its legitimization.

The structuring of conflicting is also a stage of conflict management. If the management is an activity which is directed to bring incompatible interests in accordance with certain standards, then it is necessary to raise the issue about the subject of the conflict. From a legal point of view, it is important to identify the rights and the obligations of the parties of the conflict, their quantitative and qualitative characteristics.

The last stage of conflict management is transferring it to another level (reduction). studied.

The mechanisms and forms of impact of legal norms on the behavior of participants in the conflict have been well

Firstly, this is such an impact when a manner of behavior (approved or prohibited by the state) is offered to an individual or a group of people. Secondly, the values are formed according to a legal norm, and these values are confirmed by society and state (educational action of law). Thirdly, the legal rule has the possibility of using the state coercion against those who violate its terms. If someone violates the rule then the enforcement mechanism comes into effect, the institutions and officials begin to function.

Thus, the right influences the cause of the conflict, its development, result and consequences of ending the conflict. The legal regulation of the conflict makes the system more stable, identifies the long-term development of the order and conflict resolution and thereby it is the most effective for stable social system

Modern technologies of conflict management are based on an understanding of the conflict as a confrontation between the parties, which realize the contradiction of their interests.

The resolution of the conflict is a certain conclusion. The definition of the conflict regulation is primarily related to the procedure of legal proceedings. Here the definition of "management" is also applied. It can be carried out in such forms as making decisions in administrative agencies: police, arbitration, tax inspectorate, civil and criminal proceedings. The procedure of conflict resolution is related to a definition "alternative dispute resolution". This definition is used when it is said about non-legal ways of solving the problem. Such forms include direct negotiations, reconciliation and mediation. Alternative ways of resolving conflicts assume that the parties, on their own or with the assistance of intermediaries, make some effort for overcoming the contradictions before its development will lead to the necessity of going to court justice. The application of the rules of law as part of the resolution of the conflict leads to the fact that a procedure formalizes, it is done in strict accordance with the requirements of the law.

The constitutional procedures are used to resolve conflicts which arise in the political sphere. These methods are written in the Constitution of Russian Federation and other normative acts. In resolving conflicts the state which is represented by public authorities appears to be an active and valid subject. The conflicts of this sector tend to affect a different social interest, that is why the solution requires the involvement of various political forces. The conflict resolution should be carried out mainly be legal methods.

There are the methods of resolving the conflict between the branches of government:

1) The negotiations in the form of special commissions.

2) The application of authority

3) The opportunity to find a solution for the trade union associations, association of businessman, public organizations

4) The possibilities of reorganization the branches authorities' relationship and changing the status of the state and public institutions.

The Constitutional Court Justice puts in force the judicial power and studies the disputes between public authorities according to the Constitution of Russian Federation.

Conflict can also be resolved with the help of the procedure which is called referendum, it is a direct will of people.

The constitutional procedures are clearly stated in the legislation, the conditions and the process of their application is regulated in detail.

The court justice is the leading subject of overcoming the conflicts. It has its own particular advantages and disadvantages. The court justice has a special independent status which excludes extraneous influence on its activities. Judicial procedure provides a peaceful ending of the conflict using the state coercion as the element of force. 
However, the judicial system has significant flaws: high amount of state tax, the mechanism of competition and equality of parties is not developed, the long-term consideration, a complicated procedure of consideration.

The types of proceedings are examined in detail- the civilian, the criminal and the arbitration.

Certain categories of legal conflicts are considered by special authorized state agencies. In these cases, there is a conflict between the executive power and the citizen. At present time, the administrative and judicial dispute settlement procedure is more and more widely used. However, the practice shows that the alternative ways of resolving the social conflict are the most productive once.

Negotiation is a process by which the involved parties discuss the problem with each other, trying to reach an agreement, trying to achieve at least some of the desired, making certain compromises. The main advantage of compromise is an opportunity to develop such an agreement that will satisfy the subjects of the conflict, and will help to avoid long-time procedures. The application of the negotiation process is useful in the early stages of occurrence of conflicts of law. The point of reconciliation is to reach the compromise willingness to negotiate with minimal material loss. Here the conflicting parties independently monitor the time deadline, the list of controversial issues, decisions. Conciliation is a voluntary process which is based on mutual confidence.

A consensus is an acceptable solution to the conflicting parties in the elaboration of which all members of the group consciously and rationally take part in. Consensus is not about unanimity, because the coincidence of the positions of all the participants of the process is not required. A consensus assumes the absence of direct objections and allows a neutral position. Due to the consensus the problematic situation can be resolved definitively. A compromise is an agreement based on mutual concessions, rejection of some of your requirements. The technologies of compromise are rather complicated. The methods of coordination of interests and positions are: advice, dialogue, discussion. Their use allows to identify the common values, to detect the coincidence of views and to clarify the position of the parties.

The mediation is neutral third party intervention, which aims to facilitate the process of negotiations between the conflicting parties. The main task of a mediator is to organize contacts and negotiations and to help find a formula of agreement. In the western theory this way is called "the conflict mediator". This method is used when the parties were unable to find their own solution to the problem and to reach an agreement through direct negotiations. We are given the general characteristic of these types of mediation as arbitral tribunal, arbitration, recommendatory arbitration, mediation arbitration. The practice of using mediation in conflict situations confirms its effectiveness (For example, in the countries of North America a lot of conflicts are successfully resolved in $80-90 \%$ due to the procedure of the mediation).

In Russia nowadays this sphere is actively developing. The sociological researches show the demand of alternative means of resolving social conflict.

The data of sociological research, which is obtained by observations of the author of the conflict situation which is formed in one of the educational institutions in the city of Yoshkar-Ola, select objective problems that may arise in the application of law in organizational and managerial mechanisms of resolving the conflicts.

1) The problem of efficiency of administrative activity of the head.

2) Non awareness of the society about the presence of such forms of conflict resolution which can be applied before directing the problem to the court justice or to the public authorities, also the lack of ideas about how to use an alternative way to resolve the conflict.

3) The psychological side of the conflict-the exacerbation of negative emotions

4) The absence of organizations both public and private, which could make a decision about the arising conflicts on pre-trial.

To select these problems the current conflict in the organization has been analyzed in details. Further study of the activity of organization in particular making a sociological survey on relevant issues among employees, gave us an opportunity to identify practical ways to solve these problems. Almost all respondents supported the idea to make an appropriate preparation of the contingent as part of management training courses, refresher courses. The main attention should be paid to the Conflict resolution, to put a lot of effort into studying the ways of resolving the conflict, their practical application in the future.

Society should be informed of the possibility of such means of conflict resolution, of the ways to apply them, positive and negative traits. From the state, according to the parties of the conflict depends such an important detail as strengthening an existing legislation. A wide range of specialists should be able to handle the alternative means of conflict resolution. According to the today's situation, the respondents noted that the activity of lawyers will undergo significant changes. It expands its scope and will include qualitatively new objects and relationships. So, legal professionals will need to obtain the following skills: willingness to "outside the box" in the changing legal and socio-economical environment; being able to analyze and prognosticate different situations; knowledge of basic methods of conflict resolution. 
To achieve these goals, it is important to conduct special courses and the competent organization of legal practice in law schools. The most important moment should be that students could really use their knowledge in practice that they could to be specialists of conflict resolution. The specific of the legal profession is that each representative is always in the center of the conflict. Based on the results, it is necessary to allocate the positive aspects of the use of alternative means of conflict resolution. Alternative means of resolving the conflict are confidential; they are not accompanied by record-keeping. The parties are free to control the procedure of the proceedings, to take part in the regulation of differences.

Thus, alternative means are almost multipurpose. They are applicable in all types of cases. Researchers have shown that a court as the only existing mediator in resolving conflicts can not cope with the huge influx of disputes. That is why there are opportunities for the development of alternative means in Russia, at the same time the citizens are very positive towards them.

\section{Conclusion}

Thus, the research of the scope of the law in the resolution of social conflict has shown that the system of alternative means of conflict resolution should be developed in parallel with the development of the legal system of the country. A radical reform of the judicial system must allow the opportunity for the development of the arbitral tribunal, legal advice and mediation service.

\section{References}

Proshanov, S. L. (2007). Social conflict in the writings of Russian sociologists of the early twentieth century. Sociological research, 12: 56.

Stepanov, E. I. (1999). The Conflicts in modern Russia. Problems of analysis and regulation: monograph. Moscow: Editorial, URSS: 33$34 ; 57-58 ; 177$.

The Constitution of Russia Federation, (1993).

Starygina, P. S. (2004). Organizational and managerial mechanisms for resolving social conflicts: legal aspect. The dissertation on competition of a scientific degree of candidate of sociological sciences. Moscow: Moscow state pedagogical university. 